\title{
RESENHA DO LIVRO O SENTIDO DO KARATE- DO: FACES HISTÓRICAS, PSICOLÓGICAS E FENOMENOLÓGICAS
}

BOOK REVIEW: O SENTIDO DO KARATE-DO: FACES HISTÓRICAS, PSICOLÓGICAS E FENOMENOLÓGICAS

RESEÑA DEL LIBRO EL SENTIDO DEL KARATE-DO: FACES HISTÓRICAS, PSICOLÓGICAS E FENOMENOLÓGICAS

\section{Carlos Herold Junior*}

\section{Palavras chave} Artes marciais. Filosofia.

Resenhas de livros.
Resumo: Avaliam-se as possibilidades e os limites da obra O Sentido do Karate-do, escrita por Cristiano Barreira. Embora alguns questionamentos sejam levantados, sobretudo, concernentes às opções metodológicas do autor, é endossada a relevância do livro para os estudiosos das artes marciais e, igualmente, para os estudiosos do corpo a partir de uma perspectiva filosófica.
Keywords:

Martial arts.

Philosophy.

Book reviews.

Palabras clave: Artes marciales.

Filosofía.

Reseñas de libros.
Abstract: This review assesses potential and limits of Cristiano Barreira's work O Sentido do Karate-do. Although some questions remain especially concerning the author's methodological choices, the book is relevant to those who study martial arts investigating the body from a philosophical perspective.

Resumen: Se evalúan las posibilidades y los límites de la obra El Sentido del Karatedo, escrita por Cristiano Barreira. Aunque algunos cuestionamientos sean planteados, especialmente en relación con las opciones metodológicas del autor, señalamos la importancia del libro para estudiosos de las artes marciales y también para los estudiosos del cuerpo desde una perspectiva filosófica.
*Universidade Estadual de Maringá Maringá, PR, Brasil.

E-mail: carlosherold@hotmail.com

Recebido em: 06-10-2015 Aprovado em: 22-11-2015

(c) (1) (8) Licence 
Cristiano Roque Antunes Barreira é professor da Escola de Educação Física da Universidade de São Paulo, campus de Ribeirão Preto. Em 2013, ele publicou $O$ sentido do Karate-do: faces históricas, psicológicas e fenomenológicas (BARREIRA, 2013). 0 livro de 278 páginas é resultante de sua tese de doutorado em Psicologia, defendida em 2004 na mesma universidade.

A questão que define o escopo da obra é a seguinte: como explicar o fato de praticantes e professores assumirem o karate-do como uma prática moralista e militarizante? Não lemos definições mais específicas sobre esse moralismo e militarismo. De qualquer modo, as respostas que se buscam visam a um "[...] resgate daquelas vozes arcaicas que deram luz à arte" (p.12). Essa busca se desdobra em seis capítulos onde o estudo do karate-do se dá abrindo mão da "razão instrumental" (p.11) para considerar o "[...] fenômeno originando os critérios para uma razão encarnada, orgânica" (p.12). A base metodológica do estudo se assenta nas ideias de Edmund Husserl (1859-1938). A proposta é a realização de uma "arqueologia das culturas" comprometida "com a busca do sentido originado dos produtos culturais investigados, evitando interpretá-los com um sentido externo que verse a partir de uma perspectiva autocentrada, dita também etnocêntrica e, mais delimitadamente, eurocêntrica" (p.135). Salta aos olhos o tom fenomenológico do horizonte teórico: "[...] observar o impacto animado das coisas na corporeidade em um momento pré-categorial" (p.137). Com esse pressuposto, a obra relaciona os aspectos hilético (as sensações, os impulsos, a corporeidade) e noético (a consciência, a compreensão, a reflexão) das experiências humanas. Nessa tensão, é ao aspecto hilético que se deve dirigir a "escavação regressiva da arqueologia das culturas" (p.140). Ambição importante se considerarmos o peso da dimensão noética para a herança filosófica ocidental e o modo como ela concebe a corporalidade humana.

Inicialmente, é feita uma Análise documental dos escritos de um dos alunos do Gichin Funakoshi (1858-1957)': Masatoshi Nakayama (1913-1987) é o grande divulgador do karate-do ao ambicionar torná-lo uma "arte marcial moderna e científica" (NAKAYAMA apud BARREIRA, p.79). Estudam-se as "entrelinhas" do pensamento de Nakayama, deixando de lado o que Barreira denomina de "escopo simplificado das descrições ocidentalizadas de seus textos" (p.74). Isso para evidenciar que a "verdadeira dimensão" da arte, transcendente à ênfase técnica que baliza o entendimento ocidentalizado sobre o pensamento de Nakayama, traria em si o núcleo original do karate-do inspirado nas "ideias psicológicas da obra de Gichin Funakoshi" (p.69). Esse núcleo sustenta-se na tensão entre kime e sun-dome. Kime é a "força de vontade", a energia aprimorada no treinamento para se alcançar o maior objetivo de um combate: a manutenção da própria vida por meio da eficiência mortal do golpe desferido. Já o sun-dome é a suspensão dessa força, a ser exercida de acordo com os "limites delineados pela realidade do perigo" ( $p .78$ ) que pode levar, contrariamente, à morte.

Essa dialética "define a condição de unidade do homem" (p.79), encetando a ambiguidade existente no "plano de intersecção Oriente-Ocidente" (p.79). No Oriente essa ambiguidade estimularia a busca pela harmonização dessas forças contrárias, pois elas seriam componentes do ser e da ética típicas da tragicidade humana. No Ocidente ela desembocaria em um controle externo sobre a natureza humana - tida como maléfica, agressiva e egoísta - por uma deliberação racional reforçada contra a irracionalidade do corpo. Operação que coloca o corpo em um lugar subalterno em relação à mente. Nesse ponto residiria a cisão entre o "karate moderno e científico"

1 Fundador do karate-do shotokan. 
e aquele que remontaria a uma "genuína arte marcial do oriente" (p. 79). Uma concepção unitária de corpo e mente deu espaço para que o "fantasma cartesiano" provocasse "marcas profundas na prática e no pensamento do karate" (p.79).

Barreira avalia que essa cisão se manifestou no surgimento de "duas vias do karate shotokan" (p.113), ou, "dois modelos axiais" (p.121) para a prática e o entendimento hodiernos dessa arte marcial: 1) o modelo kime, baseado nas reflexões de Funakoshi, em que a "perfeição e intenção de matar" (p.121) torna-se basilar na trágica "intenção de viver" e aciona o homem inteiro em um caminho de moralidade e espiritualidade encarnadas; e o modelo sun-dome, apropriação ocidentalizante das ideias de Funakoshi, possibilitada pelos escritos de Nakayama, viabilizando a penetração do cartesianismo no karate-do, trazendo "elementos civilizatórios" (p.125) e uma "concepção esportiva" (p.125). O sun-dome, de elemento constitutivo de uma concepção existencial, reduz-se ao controle técnico do contato do golpe, um freio exterior, artificial e racional, desvinculado de qualquer dimensão formativa da integralidade humana. Esse traço levaria o karate-do a uma "concepção do homem ocidentalizada" (p.125). Barreira adverte que não se deve entender essa oposição entre "karate tradicional" e "karate esportivo" reduzindo-a "às diferenças entre Funakoshi e Nakayama" (p121): são diferenças que "superam os autores e incluem fatores históricos que reconfiguravam a noção antropológica e a cosmovisão da conjuntura que segue ao pós-guerra" (p.121).

No capítulo 3, Arqueologia da intenção do caminho do karate, demonstra-se a importância de realizar uma "escavação rumo ao momento hilético do kime" (p.152). Barreira mostra que essa busca é complexa pela predominância do modelo sun-dome visto como "contradito do kime" (p.148), gerando uma "experiência humana dicotômica e ambígua" (p.149). Isso se manifesta na rotina dos treinos em salas com espelhos, onde "toda a atenção que era dispensada sobre a própria cinestesia, sobre o sentir o corpo e a atenção às indicações morais e psicológicas dos professores, redireciona-se mais como uma atenção visual à imagem do corpo" (p. 151). A prática dicotomizante do karate-do levou a um "aperfeiçoamento da técnica e uma deterioração do significado do gesto" (p.152). Por essa razão, os praticantes acabam buscando apenas a "estética e a funcionalidade do movimento" (p.152), tornando a arte subsumida ao esporte.

Entretanto, há "reminiscências do karatê" livres do "platonismo embrionário" (p.167). Elas foram resgatadas na análise dos depoimentos de quatro professores de karate-do. Eles são assumidos como grandes responsáveis pela introdução da modalidade no Brasil a partir de 1950. No estudo de seus depoimentos, vemos a existência de "inusitadas similaridades" (p.220) entre a prática do karate-do, enquanto ontologia e ética, e a redução fenomenológica utilizada como método de análise da experiência oriunda dessa prática. Essa confirmação se dá pela proposição de quatro categorias explicativas emanadas da fala dos professores: "corpo como sacrifício" (p.174), "corpo como vontade" (p.182), "corpo como encontro" (p.195) e "corpo como purificação" (p.204). Elas sinalizariam a existência de uma "cosmovisão oriental" (p.223) em que se explicita que o "karate parece avesso ao norte intelectual que magnetiza a bússola da mentalidade ocidental" (p.224). Por essa razão, a formação proporcionada pelo karate-do é vista como pré-categorial, alcançável pelo corpo e com o corpo. Ela seria obtida depois de se exercer um "arrefecimento ou subtração gradual das intenções externas à experiência vivencial que faz o karate-do" (p.264).

Nesse ponto, vem à luz um dilema importante para ponderarmos os méritos e os limites de Barreira (2013): ou domínio do conceito em detrimento da experiência; ou a consideração 
exclusiva da experiência corporal ou dos movimentos corporais em detrimento de qualquer reflexão sobre eles. Ao colocar como antípodas as "intenções externas" e a "experiência vivencial", Barreira (2013) nos faz pensar nas críticas feitas por Ghidetti et al. (2014) aos modos como fenomenologia é vista na Educação Física. O questionamento seria verificar se Barreira (2013), com suas opções, conseguiria pensar o karate-do de modo a compreender as "experiências silenciosas do corpo em relação à linguagem, o trânsito entre ato e significação, entre a expressão e o expresso, quer dizer, como a consciência perceptiva, dependente da temporalidade e da cultura, se relaciona com este fundo sempre pressuposto" (GHIDETTI et al., 2014, p.328).

Relacionada a essa hesitação é a abordagem que Barreira realiza sobre a história do karate-do. Nela 0 autor não se exime de tocar na recorrente dissensão entre o "karate tradicional" e o "karate esportivo". Essa oposição pode ser vista em vários trabalhos publicados no Brasil sobre o karate-do e as artes marciais de modo geral. Souza (2013) afirma:

São técnicas [as do karate-do] que surgiram para a autodefesa. Com fins bélicos, mas que porta em si mesma valores e uma busca incessante de formação e de autoconhecimento. Infelizmente, na atualidade, são poucos os mestres e escolas que ainda seguem estes princípios. 0 processo de esportivização se centra na busca pelo resultado e pela melhor performance para sobrepujar o adversário... (SOUZA, 2013, p.342).

Frosi e Mazo (2010) também manifestam insatisfação com a apreensão do karate-do que acontece no mundo contemporâneo: "Como pode uma prática que difere tanto do modelo militar e da educação liberal tradicional ter sido distorcida produzindo o karate que vemos hoje?" (FROSI; MAZO, 2010, p.307).

Barreira sustenta sua preferência pela tradição, todavia, justificando-a pela observância daquilo que escreveram os fundadores da modalidade. Para essa opção foi importante a base teórica calcada na fenomenologia e o estudo dos depoimentos coletados. Ao fazer isso ele toca na dificuldade relativa à disponibilidade de fontes primárias sobre o karate-do. Deixando de lado a desconfiança das traduções para a língua inglesa dos poucos registros escritos até agora disponíveis, o autor acerta ao escolher "estudar, justamente, a maneira como essas ideias chegaram por aqui [...]" (p.25).

Por outro lado, essa opção colide com a busca por uma "genuína arte marcial do oriente" (BARREIRA, 2013, p.79), que seria o karate-do por ele abraçado. É um desafio metodológico complexo lidar com essa busca pelo original, pelo genuíno e respeitar as apropriações e transformações incorporadas às práticas e às formas de pensá-las. Marta (2009) questiona a necessidade de se optar pela tradição ou pelas "formas genuínas" das práticas corporais. Ao discorrer sobre o processo de expansão das artes marciais japonesas e os esforços de Funakoshi em transformar o que praticava em Okinawa no "karate-do", afirma: "Negando a tradição, selecionando memórias, desqualificando costumes, Funakoshi vai gradativamente fundamentando na 'razão' e na forma, como a prática se apresentava naquele momento histórico, sua opção por um Karatê distante da influência chinesa [...]" (MARTA, 2009, p. 40). As influências culturais entre Oriente e Ocidente são complexas se considerarmos seu relacionamento marcado por débitos mútuos. Na citação abaixo se percebe que muitos dos traços tidos como deturpadores das artes marciais são momentos fundantes dessa "nova tradição": 
[...] o desejo de Funakoshi era trilhar, com a arte marcial Karatê, o mesmo caminho trilhado, anos antes, pela ginástica, enquanto possibilidade de experiência corporal na sociedade europeia, usando, para isso, um veículo poderoso, a escola (MARTA, 2009, p.41).

O que está em jogo é a viabilidade da busca das "reminiscências do Karate" pela via fenomenológica tal qual a proposta de Barreira (2013). Marta (2009) evidencia o caráter histórico e humanamente construído das práticas corporais, dos modos como elas são apreendidas, transmitidas e pensadas em tempos possuidores de diferentes traços sociais e culturais, oferecendo um anteparo relevante para se debater o núcleo das opções metodológicas de Barreira (2013).

Em que pese essas dúvidas, pode-se assumir que, ao ser capaz de originar esse debate, a obra em tela tem sua importância afirmada. Essa capacidade de levar ao diálogo e à reflexão é resultante tanto do desenvolvimento como das conclusões das análises. Na leitura, percebe-se a fluidez e o rigor do texto, deixando entrever que se está diante de uma valiosa obra no campo das artes marciais.

O livro de Barreira inicia o preenchimento de uma séria lacuna intelectual ao considerar o ensino e a prática do karate-do com um olhar voltado à filosofia. A contribuição ofertada não se dirige apenas aos estudos sobre o karate-do, mas à Educação Física de modo geral. Afinal, a presença fenomenológica em vários pesquisadores da Educação Física se dá a partir de Merleau-Ponty (1908-1961), fazendo com que a incorporação das ideias de Husserl possa estimular debates com ricos desdobramentos dessa concepção em nosso campo.

$\mathrm{Na}$ Educação Física a presença de Merleau-Ponty tem produzido reflexões de grande valor. Nóbrega (2014) explica que Merleau-Ponty estimula "horizontes de compreensão para aspectos da aprendizagem de movimentos, seja no plano motor ou cinesiológico, seja no plano simbólico, bem como no plano da historicidade do corpo, de suas práticas e sentidos" (NÓBREGA, 2014, p.1194). Por essa razão, a conhecida tensão entre continuidade e ruptura que Merleau-Ponty estabeleceu com Husserl é uma reflexão passível de maximizar as consequências que esse referencial pode ainda ter para a Educação Física. Perius (2012) diz que "Merleau-Ponty jamais parou de reler e redescobrir Husserl... Para modificá-lo? Não, para modificar-se!" (p.144). Para essa releitura a ser feita com o fito de aprimorar o uso que se fez do referencial teórico em questão, $O$ Sentido do Karate-do é um bom exemplo com grande capacidade multiplicadora. Consequentemente, a obra de Cristiano Barreira interessa não apenas aos estudos filosóficos sobre o karate-do e sobre as artes marciais, mas às investigações sobre o corpo feitas pelo prisma da filosofia.

\section{REFERÊNCIAS}

BARREIRA, Cristiano Roque Antunes. 0 sentido do karate-do: faces históricas psicológicas e fenomenológicas. Rio de Janeiro: E-papers, 2013.

FROSI, Tiago Oviedo; MAZO, Janice Zarpellon. Repensando a história do karate contada no Brasil, Revista Brasileira e Educação Física e Esporte, v. 25, n. 2, p. 297-312, 2011. 
GHIDETTI, Filipe Ferreira; ALMEIDA, Felipe Quintão de; BRACHT, Valter. Merleau-Ponty, linguagem e a fenomenologia na educação física. POIÉSIS, v. 8, p. 318-333, 2014.

MARTA, Felipe Eduardo. A memória das lutas ou o lugar do "DO": as artes marciais e a construção de um caminho oriental para a cultura corporal na cidade de São Paulo. 2009. $213 f$. (Tese de Doutorado) - Pontifícia Universidade de São Paulo: São Paulo, 2009.

NÓBREGA, Terezinha Petrúcia. Corpo e natureza em Merleau-Ponty, Movimento, v. 20, p. 1175-1196, 2014.

PERIUS, Cristiano. A definição da fenomenologia: Merleau-Ponty leitor de Husserl, Trans/Form/ Ação, v.35, n.1, p.137-146, 2012.

SOUZA, Marcel Farias de. O caminho-via marcial no cinema japonês: estudos sobre a representação do Budô em Sanshiro Sugata e Kuro Obi. Movimento, v.19, n.2, p.327-345, 2013.

\section{Apoio:}

